\title{
Т.С. Мартыненко
}

\section{ГЛОБАЛЬНАЯ СОЦИОЛОГИЯ Г. ТЕРБОРНА: ТЕОРИЯ СОЦИАЛЬНЫХ НЕРАВЕНСТВ}

\footnotetext{
Рассматривается теория сочиальных неравенств Г. Терборна, основным аналитическим приемом которой является рассмотрение неравенств как совокупности трех измерений: витального, экзистенциального и ресурсного. Представлень истоки и основные положения современной теории социального неравенства, механизмы воспроизводства системы равенства/неравенства, а также обосновывается необходимость возвращения класса в качестве главной действующей силь в борьбе с сочиальным неравенством.

Ключевые слова: социальное неравенство, Г. Терборн, класс, витальное неравенство, экзистенциальное неравенство, ресурсное неравенство.
}

Теории социального неравенства являются неотъемлемой частью социологии с момента ее возникновения. Сегодня под влиянием глобальных процессов появляется новый предмет исследований - глобальное социальное неравенство. Глобализация не только меняет масштаб изучения привычных национальных неравенств, но и порождает совершенно новые типы неравенств (например, информационное), а также накладывает «старые» типы неравенств на «новые», требуя модификации исследовательской методологии.

Теоретические подходы, призванные осмыслить глобальное социальное неравенство, представляют собой, главным образом, попытки ответить на вопрос, как взаимовлияние и взаимосвязь различных государств на межнациональном уровне сказываются на структуре неравенства внутри этих государств и можно ли говорить о едином глобальном неравенстве, или же оно представляет собой совокупность национальных. И, соответственно, представить контуры «новой» социологии. Причиной этого является то, что, на наш взгляд, для социологии изучение глобального социального неравенства не является лишь еще одной исследовательской задачей. Социология оформилась как наука, предметом которой является национальное государство, общество промышленного капитализма, трудовое общество. Выход за пределы национальных границ, их преодоление означают для социологии пересмотр собственных оснований. Несмотря на то, что роль национального государства по-прежнему велика, увеличение числа международных коммуникаций различного уровня, появление глобальных движений и организаций призывают социологов обратиться к понятию «социальное» и, возможно, пересмотреть понятие «общество». Подобной позиции придерживаются Э. Гидденс, Дж. Урри, М. Манн, А. Турен, Дж. Рифкин и другие.

Одной из попыток не только представить «портрет» социологии XXI в., но и выстроить соответствующую реальности теорию социального неравенства, находящуюся в неразрывной связи с социальной практикой, является подход шведского социолога Гёрана Терборна. По его мнению, неравенства 
становятся одной из центральных тем социологии XXI века, основной чертой которой выступает глобальность ее предмета. «Глобальная социология отличается от универсалистской тем, что исходит не из чего-то предположительно общего для всех, а из глобальной вариативности, глобальной связанности и глобальной интер-коммуникации» [1. С. 48]. Глобальной социологии свойственно принятие множественности мира, а не представление его в виде единого пространства, где действуют универсальные объяснительные механизмы.

Г. Терборн исходит из того, что любое исследование социального неравенства должно предваряться ответом на вопросы о том, что такое неравенство, чем оно отличается от различия и кто является основными субъектами отношений социального неравенства. По мнению социолога, разница между различием и неравенством предполагает некоторую общность сравниваемых объектов, то есть должно существовать представление о возможности подобного сравнения. В то же время само установление неравенства ведет к разрыву этой общности и фиксирует, по мнению Г. Терборна, нарушение нормы равенства.

Именно по этой причине точкой отсчета в изучении социального неравенства Г. Терборн считает эпоху Просвещения, когда неравенство начинает рассматриваться в качестве, прежде всего, социальной конструкции, а не естественного положения вещей. Тем не менее для шведского социолога очевидно, что идеал абсолютного равенства не может быть реализован. Вопрос о степени равенства, которое должно существовать в обществе, Г. Терборн решает при помощи концепции Амартии Сена и его работы «Возвращение к проблеме неравенства» [2]. Индийский экономист и лауреат Нобелевской премии считает, что в самом общем виде необходимая мера равенства представляет собой «равенство возможностей делать то, что мы хотим» [2]. В своих работах Г. Терборн производит попытку концептуализации данного положения, утверждая необходимость применения интегральных показателей, способных фиксировать различные измерения социального неравенства.

Признавая некоторое ограничение теории К. Маркса для рассмотрения современного социального неравенства, Г. Терборн считает марксизм наиболее ценным теоретическим основанием изучения данной проблемы в настоящее время. Одно из новшеств в изучении неравенств было обозначено феминистскими концепциями, которые не только способствовали включению иной перспективы, но и внесли значительный вклад в вопрос о соотношении различия и неравенства. Среди авторов, относящихся к этому направлению, Г. Терборн особенно выделяет Джулиет Митчелл [3], Марту Нуссбаум [4] и Джудит Батлер [5]. Соотнесение категорий «неравенство» и «различие» позволяет Г. Терборну решить несколько задач. Социолог подчеркивает, что многообразие обществ не делает их неравными. Различие представляет собой разнообразие, в том числе социальное, которое воспринимается как адекватное, желаемое и социально принимаемое. Неравенство - это различие, которое воспринимается как несправедливое, как социальный «разрыв», который социальные субъекты стремятся преодолеть, сократить. Исходя из этого, Г. Терборн, во-первых, постулирует множественность форм неравенства на фоне многообразия мировых различий и, во-вторых, выступает против поня- 
тий, тяготеющих к универсальным (экономическим, ресурсным) критериям неравенства, например «социальная стратификация».

Важным источником, способствовавшим обогащению теории социального неравенства, Г. Терборн называет теории равенства и социальной справедливости Джона Ролза [6] и Амартии Сена [2, 7]. Социологам, по мнению шведского ученого, «еще многое предстоит узнать из философского дискурса» [8. С. 14]. Обращение теоретиков социального неравенства к социальной эпидемиологии или социальной медицине было еще одним важным шагом в осознании этой проблемы. Наиболее ценными в этой области Г. Терборн называет работы Ричарда Уилкинсона $[9,10]$, в которых британский профессор демонстрирует, что рост богатства оказывает на неравенство меньшее влияние, чем более справедливое его распределение. По мнению автора, высокая степень социального неравенства, порождая высококонкурентную среду, приводит к тому, что даже в экономически обеспеченных слоях развитых обществ, например США, существует высокий уровень заболеваний и меньшая продолжительность жизни по сравнению, например, со Швецией. Р. Уилкинсон объясняет эти явления разрывом социальных отношений, отсутствием доверия в обществах с высоким уровнем неравенства, подтверждая тем самым свое утверждение, что «равенство выгодно для всех».

Наконец, на осознание глобального социального неравенства в наибольшей степени повлиял мир-системный анализ И. Валлерстайна [11], «который открыл нам глаза на систематическое мышление и изучение взаимосвязей между различными частями мира» [8. С. 14].

Кроме того, обозначая в истории теории социального неравенства наиболее ценные элементы, Г. Терборн считает необходимым зафиксировать ряд уроков, которые должны учесть социологи при построении современной теории социального неравенства:

1. Неравенство представляет собой сложный и многомерный феномен, центральной характеристикой которого является его моральная и социальная значимость. Масштабы неравенств изменяются от семьи или организации до мира в целом.

2. Особое внимание должно уделяться поиску причинных механизмов производства и воспроизводства неравенства, а также способам достижения равенства.

3. Теория неравенства должна выстраиваться в междисциплинарных рамках, включающих не только экономику и политические науки, но и медицину, психологию и другие науки. Необходим отказ от монокультурализма [8. С.15-16].

На базе указанных положений Г. Терборн производит попытку конструирования собственной теории социального неравенства. Основным аналитическим приемом Г. Терборна в изучении неравенств является постулирование множественности форм неравенств и - на этой основе - выделение трех его измерений:

1) витальное, или биологическое, неравенство фиксирует базовую характеристику человеческого существования, поскольку обращается к таким категориям, как продолжительность жизни, здоровье. Утверждение Г. Терборна «неравенства убивают» [12 С. 7] преимущественно относится именно к дан- 
ному измерению. Несмотря на первостепенную важность витального неравенства, оно часто рассматривается как различие;

2) экзистенциальное неравенство очерчивает систему иерархий, основанных на категориях включения/исключения. Примерами подобного измерения неравенства являются расизм и сексизм, выстраиваемые на основе различий между индивидами. Категориями, характеризующими экзистенциальное неравенство, выступают свобода и уважение;

3) ресурсное неравенство - распределение любых имеющих ценность в данной социальной системе ресурсов, например средств производства, верблюдов [13]. Г. Терборн подчеркивает, что в то время как большинство социологов рассматривают ресурсное неравенство как единственное проявление неравенств, оно лишь одно из измерений.

Г. Терборн отмечает, что существует два способа представления социального неравенства: «лестница» и «круги». По мнению автора, социологи чаще всего отдавали предпочтение именно лестнице и, соответственно, изучению иерархиезированных неравенств. Круги, в свою очередь, представляют собой горизонтальное представление неравенства, которое тем не менее имплицитно содержит отсылку к вертикальному. Примерами этого могут являться отношения ядро - периферия, центр - спутник, инсайдер - аутсайдер. Каждому из выделяемых Г. Терборном измерений неравенств соответствуют свои «арены» («поля» в терминологии П. Бурдье, «подсистемы» в теории Н. Лумана), в которых действуют субъекты. Так, основным пространством витального неравенства является семья, экзистенциального - сфера социального взаимодействия, ресурсное неравенство преимущественно создается отношениями собственности и занятости. Эти пространства, «арены» действия взаимосвязаны и накладываются друг на друга.

Значительное влияние на существующие неравенства оказывают 4 основных фактора дифференциации, которые включают природное богатство (индивидов, групп, территорий), систему структуризации возможностей и выгод, производительность или эффективность акторов, индивидуальные и коллективные действия по распределению ресурсов, в том числе посредством использования государства. Указанные факторы дифференциации, накладываясь друг на друга, оформляют измерения неравенства в теории Г. Терборна, оказывая на каждое из них различное влияние.

Отсюда следует, что витальное неравенство определяется через: 1) природные условия - генетические и экологические; 2) ресурсные условия (включая познавательные); 3) культурные различия (например, потребление). Витальное неравенство может сглаживаться или возрастать под действием на него экзистенциального неравенства. Экзистенциальное неравенство оформляется только под влиянием культуры - через культурную систему и первичную социализацию, хотя может иметь естественные корни (например, цвет кожи) или определяться напрямую культурой (например, посредством религии). Ресурсное неравенство определяется природными богатствами, различиями в продуктивности и систематическим структурированием возможностей и выгод. Классовая борьба является формой действий по распределению ресурсов.

Г. Терборн подробно рассматривает систему механизмов производства, воспроизводства и изменения социальных неравенств, которая представляет 
собой совокупность четырех дуальных позиций, где каждому механизму неравенства противостоит свой механизм равенства. Механизмами неравенства являются дистанцирование, исключение, иерархизация (отношения господства и подчинения) и эксплуатация. Им противостоят такие механизмы равенства, как компенсация (или поддержка), включение, организационное/институциональное выравнивание и перераспределение (см. подробнее [14]). Эти механизмы кумулятивны. Все механизмы неравенства, кроме дистанцирования, направленно помещают одних субъектов в более привилегированное положение, чем других [13. С. 14]. Причиной этого является то, что отношения неравенства располагаются между двумя полюсами. С одной стороны, отношения неравенства между субъектами могут носить ненаправленный характер, например, А получает большее преимущество, чем Б, за счет более удачной стартовой позиции или собственного поведения. Этот механизм Г. Терборн обозначает как дистанцирование. Противоположный полюс составляют отношения неравенства, в которых А направленно использует Б для достижения и сохранения своего положения. Этим механизмом является эксплуатация [13. С. 11-12]. Социальное неравенство всегда ограничено. Его границы меняются с течением времени и на различных территориях. В изучении неравенств наибольшее внимание необходимо уделять именно барьерам, фиксирующим и воспроизводящим это неравенство.

Характеризуя неравенство и равенство в современных обществах, Г. Терборн отмечает, что, несмотря на разнообразную динамику этих отношений в различных регионах, можно выявить некоторые общие тенденции. Так, витальное неравенство со второй половины прошлого века усиливается, особенно в отношении Африки и ряда других регионов, в связи с распространением заболеваний. Экзистенциальное неравенство уменьшается, начиная с появления движений за равные права меньшинств и других слоев, возникающих также со второй половины XX в. Ресурсное же неравенство, особенно экономическое, неизменно растет. Распад СССР, по мнению Г. Терборна, серьезно усугубил этот процесс.

Обращаясь к изучению глобального неравенства в современном мире, Г. Терборн отмечает, что «глобальные последствия не обязательно глобально продуцируются» [14. С. 40]. Тем самым социолог предостерегает исследователей от недооценки роли государства в современном мире.

Глобальное неравенство может быть, в частности, результатом механизма дистанцирования, действующим в глобальном масштабе, также неравенства возникают из различных комбинаций глобального и национального. Среди основных комбинаций социолог выделяет следующие:

1) преимущественно национальные движущие силы неравенства;

2) глобальная история и национальное неравенство;

3) преимущественно транзитивные глобальные процессы неравенства.

«Каждая из трех возможных комбинаций способна продуцировать одну и ту же глобальную картину или показатели неравенства» [14. С. 41]. Тем самым глобальность влияет на национальный уровень посредством глобальной истории, глобального распространения и глобальных обстоятельств, где важнейшими процессами являются процессы глобального переплетения (то есть взаимоналожение и взаимопересечение групп акторов на различных 
уровнях) и сети, а также глобальные потоки, роль которых также неоднозначна. Эти процессы влияют на неравенство, порождая локальные процессы его продуцирования, среди которых такие важнейшие механизмы:

1) глобальное (или международное) влияние на создание национальных программ;

2) формирование моделей институтов, означающее разработку и предписание создания национальных институтов определенного рода (две формы: во-первых, либерализация посредством дерегуляции, приватизации и открытия границ, где главными движущими силами были МВФ, Всемирный банк и стоящее за ними правительство США; во-вторых, движения за права человека в целом и в частности, в интересах слабых и дискриминируемых категорий, разрабатываемые ООН посредством таких инструментов, как конференции и конвенции;

3) политические предписания (например, в рамках «политики реструктуризации или политики над контролем рождаемости) [14].

По мнению Г. Терборна, новый глобальный порядок носит классовый характер, поскольку снижающееся межнациональное неравенство (по сравнению с выдвинувшимся на первый план в середине XX в. глобальным неравенством между странами) подчеркивает возрастающее социальное неравенство внутри стран. Шведский социолог видит 2 основных варианта развития класса в современном мире - это развитие среднего класса и консолидация рабочего [15]. Для социолога, на которого оказали наибольшее влияние, по его собственному признанию, К. Маркс, М. Вебер, Э. Томпсон, П. Андерсон, А. Грамши, А. Лефевр и Л. Альтюссер [16], наиболее приемлемым с идеологической точки зрения является второй вариант. В ситуации роста среднего класса Г. Терборн видит две возможные перспективы: появление глобального среднего класса потребителей или политизация среднего класса, в котором он также видит наличие протестного потенциала, который может иметь непредсказуемые последствия.

Деиндустриализация Европы и Северной Америки заставляет Г. Терборна искать новые пространства для консолидации рабочего класса, которые он находит, прежде всего, в Азии: «Эстафета индустриального рабочего класса была передана Китаю, развивающемуся центру мирового производства товаров массового потребления» [15. С. 5]. Наконец, еще одной возможностью для объединения рабочего класса служит мобилизация разнородных низших слоев, прежде всего, стран Азии, Африки, Латинской Америки, преградой для которой служат в настоящее время такие факторы, как религия, этничность, вид занятости и т.п. В качестве примера Г. Терборн приводит тайское движение «красных футболок», которое «стало важнейшей политической силой страны на выборах в июле 2011 года» [15. С. 5].

Оценивая перспективы реализации своих прогнозов, Г. Терборн замечает: «Самый вероятный сценарий развития событий - постепенное воплощение всех четырех вариантов. Влияние каждого из вариантов предсказать невозможно, и, кроме того, оценка смысла и значимости результатов, вероятнее всего, будет предметом дискуссии» [15]. «В то время как национальные государства остаются внушительными структурами, и классовые конфликты в основном остаются внутринациональными, новый этап глобального нера- 
венства являет собой возрождение значимости класса и падение значимости нации как определяющих факторов человеческой жизни» [15. С. 5]. Рассматривая перспективы для увеличения равенства, Г. Терборн считает возможным формирование нового общественного движения, союза в борьбе за равенство. Тем не менее нет однозначных предпосылок для подобного сценария, а потому важную роль продолжает играть государство. Именно способность и возможность государственного перераспределения могут быть мощным механизмом социального равенства даже в условиях капитализма [8. С. 23].

Современная социологическая теория выстраивает различные исследовательские подходы и использует многообразные методы при анализе глобального социального неравенства. На наш взгляд, наиболее адекватным способом разграничения подходов является обращение к основополагающим категориям, которых в изучении глобальных неравенств как минимум две «сеть» и «класс». Каждый из подходов предполагает соответствующее видение социальной реальности, определенное представление о структуре социального пространства. Теории, базирующиеся на понятии «сеть» или близких к нему понятиях (например, М. Кастельс, Дж. Рифкин, Дж. Урри и другие), представляют социальное пространство как совокупность горизонтальных и вертикальных «каналов» и «потоков», где важнейшее место занимают «узлы» - точки наибольшей концентрации социальных отношений, возможностей, ресурсов, жизненных шансов, «доступ» к которым имеет решающее значение для определения положения социальной единицы в пространстве. Подобный сетевой подход оставляет возможность для социологического и социального конструктивизма. В самом ущемленном положении находятся субъекты, не имеющие доступа к сети.

Теории, базирующиеся на понятии «класс», опираются на иное представление о социальной реальности. Субъектами глобального социального неравенства являются «реальные» социальные единицы - классы. Отношения транснациональных классов в теориях таких ученых, как Л. Скляр, В. Робинсон, Дж. Харрис, И. Валлерстайн, охватывают весь мир и базируются преимущественно на экономических критериях. Подход Г. Терборна, несомненно, относится к тем, которые опираются на понятие «класс», тем не менее выгодно выделяется на их фоне. Причиной этому является его стремление учесть культурное многообразие мира, специфику отдельных регионов, а потому выявить, прежде всего, механизмы неравенства, а не критерии. Важным достижением социолога, на наш взгляд, является обращение к глобальным неравенствам, учитывая глобальную историю отдельных регионов, транзитивные процессы. По причине своей сложности, многоуровневого и многоаспектного анализа, а также лишь небольшого числа переведенных на русский язык статей теория Г. Терборна почти неизвестна российскому исследователю, но, с нашей точки зрения, заслуживает внимания и способна выступить инструментом в изучении глобальных неравенств.

Обобщая вышесказанное, отметим, что теория социальных неравенств Г. Терборна представляет собой попытку построения теории глобальных неравенств, базирующейся на понятии «класс», основным аналитическим приемом которой является выделение трех измерений неравенства: витального, экзистенциального и ресурсного. Теория шведского социолога предлагает во многом марксистское понимание неравенства, дополняя его теори- 
ей справедливости и некоторыми положениями феминистской социологии и социальной медицины. Учитывая возникающую множественность показателей и индикаторов социального неравенства в соответствии с предложенной Г. Терборном схемой его изучения, основной задачей социологии в настоящее время является тщательный анализ отношений глобального неравенства, возникающих как результат противоречивого взаимодействия глобальных и национальных процессов, с целью выявления динамики этих отношений. Неравенства, предстающие в виде совокупности разнонаправленных процессов, требуют как специального рассмотрения отдельных проявлений, так и синтезирующего взгляда. Теоретическую позицию Г. Терборна невозможно отделить от его идеологических установок, в соответствии с которыми борьба за социальное неравенство не должна прекращаться, и понятие «класс» вновь ложится в основу этого движения за равенство.

\section{Литература}

1. Терборн Г. Начало второго века социологии: времена рефлексивности, пространств идентичности и узлы знания // Социологическое обозрение. 2001. Т. 1, №1. С. 46-49.

2. Sen A. Inequality Reexamined. Cambridge, MA: Harvard University Press, 1992. 207 p.

3. Mitchell J. Women - the Longest Revolution // New Left Review. 1966. № 40. C. 11-37.

4. Nussbaum M. Women and Development. New York: Cambridge University Press, 2001. 312 p.

5. Butler J. Gender Trouble. New York: Routledge, 1990. 172 p.

6. Rawls J. A Theory of Justice. Cambridge; MA: Harvard University Press, 1971. 607 p.

7. Sen A. The Idea of Justice. London: Penguin, 2009. 467 p.

8. Therborn $G$. Inequalities and Latin America: From the Enlightenment to the $21^{\text {st }}$ Century // Working Paper Series. 2011. № 1. P. 1-31.

9. Wilkinson $R$. G. The Impact of Inequality: How to Make Sick Societies Healthier. New York: The New Press, 2005. 368 p.

10. Wilkinson R., Pickett K. The Spirit Level. London: Allen Lane, 2010. 400 p.

11. Wallerstein I. The Modern World System. New York: Academic Press, 1974. 233 p.

12. Therborn G. The Killing Fields of Inequality. Cambridge; Malden: Polity Press, 2013. 180 p.

13. Therborn $G$. Inequalities of the World: New Theoretical Frameworks, Multiple Empirical Approaches. London: Verso, 2006. 332 p.

14. Терборн Г. Глобализация и неравенство: проблемы концептуализации и объяснения // Социологическое обозрение. 2005. Т. 4, № 1. С. 31-62.

15. Терборн Г. Глобальное неравенство: возвращение класса // Глобальный диалог. 2011. T. 2, № 1. C. 3-5.

16. Интервью с профессором Йораном Терборном // Журнал социологии и социальной антропологии. 2013. № 1. С. 5-19.

Martynenko Tatyana S. Lomonosov Moscow State University (Moscow, Russian Federation).

E-mail: ts.martynenko@gmail.com DOI 10.17223/1998863X/29/20

\section{G. THERBORN'S GLOBAL SOCIOLOGY: THEORY OF SOCIAL INEQUALITIES}

Keywords: social inequality, G. Therborn, class, vital inequality, existential inequality, resource inequality.

The article is devoted to G. Therborn's theory of social inequalities, its major analytical technique - to examine inequalities as a set of three measurements: vital, existential and resource. It presents origins and traits of the contemporary theory of social inequality, the mechanisms of reproduction of equality / inequality, as well as the necessity of returning to class as the main force in the fight with social inequality.

\section{References}

1. Therborn G. Nachalo vtorogo veka sotsiologii: vremena refleksivnosti, prostranstv identichnosti i uzly znaniya [The beginning of the second century of sociology: times of reflexivity, spaces of identity and knowledge nodes]. Sotsiologicheskoe obozrenie - Sociological Review, 2001, vol. 1, no. 1, pp. 46-49. 
2. Sen A. Inequality Reexamined. Cambridge, MA: Harvard University Press, 1992. 207 p.

3. Mitchell J. Women - the Longest Revolution. New Left Review, 1966, no. 40, pp. 11-37.

4. Nussbaum M. Women and Development. New York: Cambridge University Press, 2001. 312 p.

5. Butler J. Gender Trouble. New York: Routledge, 1990. 172 p.

6. Rawls J. A Theory of Justice. Cambridge; MA: Harvard University Press, 1971. 607 p.

7. Sen A. The Idea of Justice. London: Penguin, 2009. 467 p.

8. Therborn G. Inequalities and Latin America: From the Enlightenment to the 21 st Century. Working Paper Series, 2011, no. 1, pp. 1-31.

9. Wilkinson R.G. The Impact of Inequality: How to Make Sick Societies Healthier. New York: The New Press, 2005. 368 p.

10. Wilkinson R., Pickett K. The Spirit Level. London: Allen Lane, 2010. 400 p.

11. Wallerstein I. The Modern World System. New York: Academic Press, 1974. 233 p.

12. Therborn G. The Killing Fields of Inequality. Cambridge; Malden: Polity Press, 2013. 180 p.

13. Therborn G. Inequalities of the World: New Theoretical Frameworks, Multiple Empirical Approaches. London: Verso, 2006. 332 p.

14. Therborn G. Globalizatsiya i neravenstvo: problemy kontseptualizatsii i ob"yasneniya [Globalization and Inequality: Problems of conceptualization and explanation]. Sotsiologicheskoe obozrenie Sociological Review, 2005, vol. 4, no. 1, pp. 31-62.

15. Therborn G. Global'noe neravenstvo: vozvrashchenie klassa [Global inequality: the return of class]. Global'nyy dialog, 2011, vol. 2, no. 1, pp. 3-5.

16. Interview with Professor Göran Therborn. Zhurnal sotsiologii $i$ sotsial'noy antropologii - The Journal of Sociology and Social Anthropology, 2013, no. 1, pp. 5-19. (In Russian). 